\title{
Brokering academic literacies in a community of practice
}

\section{Lynne Gornall}

University of Central Lancashire, UK

\section{Abstract}

This paper examines the 'academic literacies' approach to supporting postgraduate international students in the business school of a post-92 English university. The support service was evaluated with appreciative inquiry methods, consulting students and academics. The most helpful support, according to students and academics, came from the 'academic literacies' approach, which was enhanced, and enabled, because it was linked to two other ideas: communities of practice, and the learning developer as a broker.

Keywords: academic literacies; international students; community of practice; legitimate peripheral participation; learning development; study skills; brokering; deficit model; appreciative inquiry.

\section{Context}

This research, conducted in the business school of a post-92 institution (former polytechnic), focuses on the support provided for international postgraduate students by the International Student Support (ISS) tutor, a senior lecturer in the School. The support comprises a weekly learning development session tailored to modules and assessments, which is on the students' timetable and presented as part of the students' programme of study, one-to-one tutorials and learning resources on a virtual learning environment (VLE).

\section{Introduction}

The learning development provided for non-traditional, widening participation and international learners in higher education has been roundly criticised from the standpoint of 
'academic literacies', developed primarily by Lea and Street (1998). The argument is that if institutions assume that all problems lie with the learner, the 'deficit approach' to supporting them will prevail and will be inadequate (Lea and Street, 1998; Biggs, 2003; Wingate, 2006; Shreeve, 2007; Wingate, 2011). A deficit approach to supporting the learning development of students is likely to consist of text-focused study skills such as instruction on essay structure, grammar and punctuation and accurate referencing protocol (not practice), which aim to plug the 'skills gap'. However, Lea and Street (1998), Wingate (2006), and others, challenge the notion that such atomised study skills are discrete, homogenous and based on empirical criteria, and therefore argue that they are not learnable or transferable. Wingate is damning and argues that this kind of study skills provision is based on outdated perspectives on students, skills and learning and is in general 'largely inadequate' (2011, p.27).

Unlike a skills approach to supporting students, the hallmark of an 'academic literacies' approach is the extent to which 'practice is privileged above text' (Lillis and Scott, 2007, p.10). From a critical perspective, the 'academic literacies' model (Lea and Street, 1998; 2006) sees reading and writing or literacies as cultural and social practices and focuses on the epistemology of literacy at an institutional level. It is concerned with meaning-making, identity, power, and authority, and foregrounds the institutional nature of what counts as knowledge in any particular academic context (Lea and Street, 2006, p.367). An 'academic literacies' approach provides valuable insights into other approaches (Wingate, 2011. p.28) but research in the field is dominated by small scale projects, which 'inhibit theoretical developments' (Lillis and Scott, 2007 p.21) and although used to underpin course design, 'academic literacies' as an approach, has not been easily translated into a pedagogy (Lea, 2004).

This lack of pedagogic influence is apparent with much of the support for international students, where writing and/or language support such as English for Academic Purposes (EAP) programmes, provided centrally and often generic, predominate. Such programmes which focus on skills not literacy practices, rarely help students to become familiar with the 'discourse conventions of their own disciplines' (Wingate, 2015, p.39) and without addressing the 'complex, socially-situated set of meaning-making practices' they will not fulfil the learning needs of students (Gourlay, 2009, p.182). Perhaps indicative of the inadequacy of skills or EAP programmes is the widely held view that international students are a burden on teaching because of problems with English language competency, 
academic writing, plagiarism, lack of critical analysis and independent learning (Fallon and Berman Brown, 1999; Kingston and Forland, 2008; Hall and Sung, 2009 and others).

However, it is also the case that for many subject lecturers, working with international students may facilitate a greater awareness of their own literacy practices, resulting in more overt literacy teaching. Like 'canaries in the coal mine' they show us the challenges (Ryan and Carroll, 2005, pp.9-10) and perhaps make us aware of the diversity of literacy practices. As a result, many subject lecturers will often take responsibility for inducting students into the writing practices of their discipline themselves rather than relying solely on centralised skills or EAP support. However, subject lecturers may not recognise the complexity (Lillis and Scott, 2007, p.19) or only have a 'tacit understanding of the discipline's discourses and literacy conventions' and therefore are not best placed to offer useful feedback on student writing (Wingate, 2015, p.58). In addition, the tendency to focus on the international learner's deficits can obscure the complexity of academic literacies, and might result in neglecting to take into account the 'gaps between' subject lecturers' 'expectations and student interpretations of what is involved in student writing' (Lea and Street, 1998, p.159).

To summarise then, international students are often viewed as problematic and a burden on teaching because they are assumed to have a skills deficit, a view which is partly due to a lack of understanding of the complexity of discipline specific 'academic literacies'. Students are frequently supported by centralised services to develop their skills but the skills provision does not address all their needs and the process does not facilitate a greater understanding of discipline specific literacies for either students or staff nor does it influence practice. This research examines whether an 'academic literacies' approach to learning development, where the learning developer brokers between staff and students within a specific learning community, is a more effective way of supporting the learning of international students.

\section{The role of communities of practice (CoP) in supporting an academic literacies approach}

According to Wenger (1998), a community of practice is a group of people or learners who 'share a concern or passion for something they do, and learn how to do it better as they interact regularly' (Wenger-Trayner and Wenger-Trayner, 2011, no pagination). This 
interaction requires 'community maintenance' to build and sustain it (Wenger, 1998, p.73) and the active participation of members, including students, to develop it (Shreeve, 2007). Similar to 'academic literacies', CoP concepts have developed from looking at learning through an anthropological lens rather than a psychological one, where learners might be seen as 'students' in the psychological view but 'members of a community of practice' in the anthropological view (Barab and Duffy 2000). Learning is seen as fundamentally a social phenomenon which takes place through participation within a community of practice (Wenger, 1998), both between students and tutors and between students (Taha and Cox, 2010, p.397). The rubric for learning which takes place in a community of practice is ‘legitimate peripheral participation’ (LPP) (Lave and Wenger, 1991), which focuses on the relationships between 'old-timers', or experienced full members of a community of practice, and 'newcomers' and the power, access and transparency aspects inherent in the relationship which allow LPP or learning to take place. Learners begin their learning on the edges of a group where their initial position participating on the periphery is seen as legitimate, early-stages learning.

Such participation requires access to a 'wide range of ongoing activity, old-timers, and other members of the community; and to information, resources and opportunities for participation' (Lave and Wenger, 1991, p.100). International students are at a disadvantage because of the 'regressive movement they experienced by leaving a community of practice in their country of origin, in which they had been full participants' (Halic et al, 2009, p.90). In addition, there are barriers to accessing and participating in the CoP because of language competency and lack of cultural capital (Bourdieu,1986) or educational knowledge of the new learning environment. For example, international students may not easily understand informal verbal instructions about assessments or catch any colloquialisms, asides or cultural references. Nor, as discussed earlier, is the 'practice' of higher education learning transparent, nor ways of doing things explicit. So it is clear that for international students there are barriers to entering the CoP via LPP and we cannot assume they will 'learn practices and adopt new identities simply through exposure to the environment' (Gourlay, 2009, p.183). However, international student and faculty members' peer support seminars can provide a 'safe space' for students to engage in legitimate peripheral participation away from the constraints and issues they encounter in endeavouring to engage in their wider native speaker community of practice (Samimy et al, 2011). 
In addition, international students already have established literacy practices which may be at odds with the new community's 'privileged ways of communicating' and where tutors are not aware of the privilege of their own literary practices, they offer no help (Wingate, 2015, p.110), as discussed earlier. There are then barriers to students entering the CoP not least due to subject lecturers' unawareness of their own and other literacy practices. This, perhaps, is where working with students and their subject lecturers within the CoP can facilitate awareness on both sides. For this to happen the learning development practitioner needs to be positioned between students and subject lecturers on the periphery of both groups, and take on a brokering role.

\section{The role of brokering in supporting an academic literacies approach}

Brokering, in higher education, could be considered an 'intentional act' to collaborate with people to work towards change and development (Jackson, 2003, p.5). By 'spanning boundaries' between lecturers and students, learning developers can become a sort of 'cultural broker' (Stage and Manning, 1992, p.41) or 'go-between, one who advocates on behalf of another individual or group' (Jezewski and Sotnik, 2001) mediating between groups of people to reduce conflict or invoke change (Jezewski, 1990). This might involve challenging assumptions about students, influencing the academic environment by, for example, participating in working groups, and advising students on how to approach lecturers to get solutions (Stage and Manning, 1992, p.43). In relation to boundaryspanning, connectivity among people is an essential element to a progressive community of practice which could involve brokering relationships between 'people who need to talk or between people who need help and people who can offer help' (Wenger, 2001, p.232). Subject lecturers are often structurally equivalent in the sense that they have the same contacts and access the same information, resulting in information gaps between social networks or 'structural holes' (Burt, 2005). Arguably, learning developers who know the policy, practice and views of a number of groups, can at a basic level 'make people on both sides of a structural hole aware of interests and difficulties in the other group' and at a higher level transfer best practice between groups, far more effectively than people confined within those groups (Burt, 2005, p.61). In relation to the 'academic literacies' approach, 'literacy brokering' is where brokers 'bridge linguistic, cultural and textual divides for others' (Perry, 2009, p.256). 
The ISS tutor brokering role within the School's CoP of staff and international students, where regular interaction and exchanging information between both parties takes place, enables and is pivotal to the 'academic literacies' approach.

\section{Research methods}

The evidence presented here was originally gathered to critically examine the quality of the ISS tutor's practice. However, for this paper the evidence has been re-evaluated in order to specifically examine the significance of the 'academic literacies' approach to developing international students. Poor English language competency is assumed to be the reason why international students struggle, which contributes to the view that the function of international student support is to improve students' English. In other words, the deficit approach dominates the discourse. In order to change this discourse, a participatory stakeholder evaluation using the appreciative inquiry model (Cooperrider et al, 2008) has been used.

The appreciative inquiry (Al) cycle typically has four distinct stages: discovery, dream, design and delivery. However, only the discovery and dream stages have been undertaken for this study due to length of time the full Al process takes in terms of redesigning and delivering outcomes as a result of research findings. At the 'discovery' stage information was gathered about what is positive about the past or present in order to critically evaluate the current learning development provision. Next came the 'dream' stage where a positive future was envisioned or imagined to ascertain and analyse the stakeholders' vision of an ideal learning development provision.

Al has limitations and has been criticised for having a 'strengths-based orientation' and the propensity to ignore negative aspects (Reed, 2007). However, although things that work well will be discovered by asking questions such as 'what works well?' rather than focusing on what problems there might be, it is also the case that where important aspects of a service or practice are not identified as positive or effective through an appreciative inquiry, this could be a strong indication that they are not (Cousin, 2009, p.173). 


\section{Recruitment and data collection}

Data has been drawn from paired interviews where participants interview each other in pairs and note down each other's responses, involving 25 participants in total; 10 members of academic staff and 15 international students from the Business School from a range of business and management disciplines. Staff and students were asked different questions and undertook paired interviews separately. Staff were encouraged to explore questions such as: 'for you personally, what is the main benefit of having ISS tutors in the Business School?' (discovery stage) and 'if resources, including time, were unlimited, how would learning development tutors and subject lecturers work together?' (dream stage).

Students undertook paired interviews in three separate groups of eight, four and three according to their availability. Student interview questions were designed to elicit what they found useful about the support provided such as 'during one-to-one tutorials, what was the best thing that happened? When did you think 'I'm happy I came for a tutorial?' (discovery stage) and 'if you were a UK business school dean and had unlimited money, what support would you provide for international students in your school?' (dream stage). Information and consent forms were carefully but simply constructed to maximise understanding of the project and to fulfil ethical requirements.

\section{Data analysis}

Written responses were transcribed on a master sheet and a content analysis undertaken. Responses were categorised using a basic thematic coding technique (see Saldana, 2009) according to whether the support described by respondents had the hallmark of 'academic literacies' (practice over text) or was generic study skills in nature. The support provided for students is multifaceted, involving timetabled learning development sessions, one-to-one tutorials and VLE study skills resources. Therefore, it has sometimes been difficult to determine which element participants are referring to in their responses. Responses such as 'guide to get materials from university database' and 'help with paraphrasing' can be accurately categorised as study skills. However, responses such as 'get more journal information support' and 'had a proper understanding of writing academic essays' could be categorised as study skills or academic literacies because it is not known whether the students were referring to in-class discussion around literacy practices or 
generic VLE material. Such ambiguous responses were excluded from the analysis. One of the questions specifically asked about the usefulness of the VLE and as that only contains study skills resources, it was excluded also.

\section{Findings and discussion}

\section{The student responses}

Looking at the discovery stage data overall, the elements of ISS tutor support indicated as most useful or helpful were academic literacies (AL) 51 mentions. Study skills (SS) had 31 mentions in total. 12 of the respondents said learning development sessions were most useful, one stated that one-to-one tutorials were most useful, one said email support and one said that the VLE was most useful.

\section{Academic literacies}

Typical ISS tutor learning development activity involves, for example, discussion about what counts as knowledge or good work in the particular academic context, whether that be discipline-specific (for example, the MBA emphasises theory, while Finance and Investment focus on models and calculations) or lecturer-specific (lecturer $X$ wants to focus on self-awareness in your reflective writing, lecturer $Y$ focuses on language and grammar, for example). So, in classes and tutorials, the activities and discussion are focused on cultural and social practices (Lea and Street, 1998). Students greatly valued this element of their support and talked a lot about deconstructing assignment instructions and discussing what the subject lecturer wants from them. Showing an awareness of the complexity involved and understanding that different practices have different requirements, for example, these are examples from the responses of students valuing the hallmark of an 'academic literacies' approach in that their responses indicate they value practice being 'privileged above text' (Lillis and Scott, 2007, p.10):

'How to answer assignment questions properly and knowing the requirement of each module tutor'.

'Help student to understand what the assignment requires'. 
'Breaking down the complex assignments into simple ones (parts)'.

'Understand what tutor wants from my work'.

Any instruction or discussion on referencing will be focused on practice rather than protocol, because teaching where to put brackets etc., does not explain the practice of referencing where knowledge from literature may be contested as well as used as evidence (Wingate, 2006, p.463). So instead of focusing on technical aspects, we talk about who writes journal articles, books etc. and who decides whether they are authoritative, why they write them and what for, and within our academic tradition, what you are expected to do with them and their relationship to themselves and their own ideas. For example, this mention of referencing refers to practice not protocol:

'Was taught how to use academic ref'.

And these examples illustrate how students have engaged with what counts as knowledge in their particular academic context (Lea and Street, 2006, p.367):

'Help student find literature of studied topic'.

'How to choose the references, like they (ISS tutors) don't suggest text books'.

\section{Brokering and communities of practice (CoP)}

Access to the community of practice (CoP) and its members is critical for learning (Lave and Wenger, 1991, p.101) but as discussed above (Gourlay, 2009; Wingate, 2015), there are barriers to international students participating in the CoP of their discipline via LPP due to access to 'old timers', language competence, and less cultural capital. However, in learning development sessions the ISS tutor positions herself as a more experienced peer and as discussed earlier, this can become a 'safe' space for students to engage in LPP (Samimy et al, 2011). It is argued here that offering such a 'space' and brokering between the institutional practices, subject lecturers and students, affords better access to the CoP for students as evidenced in these examples: 
'As a group when we brainstorm it gives me the idea on how to best approach my coursework to score high mark'.

'Practise and discuss as a group in front of IS tutor'.

'How to write a reflective essay and she explained clearly to me'.

'The information I heard about the residential trip'.

Interestingly, there was also understanding of the brokering relationship:

'Been able to determine what the lecturers want through the ISS tutor's lectures'.

'ISS tutor sorted academic issue with other course tutor'.

\section{Study skills}

So it would seem that 'academic literacies', CoP and a brokering approach to support are valued by students, and mentioned more than stand-alone VLE resources and textfocused, atomised technical study skills, which characteristically involve instruction on essay structure, grammar, punctuation and accurate referencing protocol (not practice). Interestingly, when study skills were mentioned in responses, the information was somewhat shallow in comparison, atomised and not associated with their assignments, tutors or practice, for example:

'Making using of the e-learn and library online resources'.

'How to write essays, paraphrase properly'.

'Learning how to paraphrase effectively'.

\section{The staff responses}

Before looking in detail at the staff responses, it is interesting to note here that one or two subject lecturers did also refer to study skills as being very useful however, their 
responses are entirely in keeping with deficit thinking about students, focusing on students' inadequacies rather than the possible gaps between their expectations and student interpretations (Lea and Street, 1998, p.159). This could also indicate that they themselves may not 'recognise the complexity' (Lillis and Scott, 2007, p.19) or only have a 'tacit understanding of the discipline's discourses' (Wingate, 2015, p.58). As discussed earlier the 'deficit' view of international students prevails in that they are simply lacking the skills for writing; and from the responses in this study, some staff have the view that the ISS tutor is there to plug the skills gap or help out the subject lecturer, for example:

'Time saving for the tutor ...can refer students with problems ...Concentrate on delivering the module, not referencing and writing'.

'Have gone to service on one or two occasions with students with language problems'.

'Helps module tutors in coping with a diverse range of students'.

\section{Brokering Academic Literacies}

However, the majority of the staff responses recognised literacy as cultural and social practice and valued the relationship with the ISS tutor as a fellow member of the CoP. Many responses indicated that collaboration between subject lecturers and ISS tutors has helped to make assignments and practice transparent and accessible to students, for example:

'That there was someone able to contextualise and help students make sense of what lecturers might deliver to students in the classroom'.

'Gives students a second chance at better understanding of module material if ISS tutor discusses in class'.

'Non-standard requirements/various expectations - sharing module information and assignment details is crucial ... generic advice might be detrimental to students', 'sharing module information means everyone is on the same script'. 
'He found particularly useful your services regarding giving you assignment essay titles and you deconstructing and explaining everything the title means ... Makes assessment briefs a lot clearer to students'.

\section{Collaboration influencing practice}

Doing things better by 'interacting regularly' in the CoP (Wenger-Trayner and WengerTrayner, 2011) and brokering between staff and students to influence the academic environment (Stage and Manning, 1992, p.43) have influenced the practice of subject lecturers.

'Final year students - first assignment, poor performance - students upset.

Working with tutors is ISS (tutors) to make developments. Eg what does a good assignment look like?'

'From the research side, helps the reflective practice of tutors which makes the student experience better'.

Brokering provided knowledge where there were 'structural holes' and transferred best practice between groups (Burt, 2005).

'Helped me to reflect on the language I use and the cultural stereotypes I hold. This comes through professional relationship ... can use ISS tutor as a sounding board for wording of assignments etc.'.

'First came here not having experience of teaching international students. I went through MIP [module information pack including module content, schedule and assessment instructions] and was able to get feedback on the wording and structure of the assignment brief - it makes a lot of difference. I asked for help if MIP will work with students'.

'Helpful because it means I can check my assumptions - if the [ISS] tutor is aware of what my module is about, I am able to pre-empt any lack of understanding about things I might assume are not problematic for students'. 
'Collaborating helps us clarify things and helps understanding. Gives us a second opportunity to make something right if I had assumed something incorrectly'.

The connectivity among people is an essential element to a progressive community of practice (Wenger, 2001) and responses indicated the importance of ISS tutor being situated in the School, for example:

'Would be difficult to manage if not in school, impossible because of different styles/requirements/subject areas/assignments between schools'.

'Not ethical or fair for the international students if we don't have ISS tutors work with us as part of the delivery team - mutually supportive working relationship'.

Responses indicate that through collaboration we can see elements of LPP (Lave and Wenger, 1991) with the learning developer taking on the role of the 'old-timer' with subject lecturers being the 'newcomers' to learning development.

'I liked the engagement with ISS tutor and her personal approach and candid discussions between myself and a specialist colleague ... Another plus is personal relationship and proximity'.

'Someone to talk to about issues and access ...Your accessibility and how we used that to support students'.

\section{The dream stage}

The 'dream stage' data was not as rich as the 'discovery stage' however, at the 'dream stage' there was a strong sense that support was good, as both students and staff indicated they wanted more of the same rather than dreaming of something different. Where the reality and the ideal were different, it was mostly in relation to things which were outside the remit of ISS tutors such as more opportunities for work placements or reduction in fees.

\section{Conclusions}


In this paper, the extent to which the 'academic literacies' approach is practised and valued in the context of a post-92 business school has been examined. The evidence echoes the literature in relation to study skills, in that the staff responses equate study skills with deficit thinking about students, and where students mentioned study skills the discourse was atomised and relatively shallow in comparison to when they were talking about what has been considered as 'academic literacies' support. Also reflected, was a lack of understanding by some staff of the complexity of the discourse and literacy conventions of their own practice, perhaps explaining their need to outsource literacy work to the ISS tutor rather than collaborating. However, there was a clear indication that staff value highly the collaboration which promotes an epistemological interrogation of their course materials and assessments, which is the hallmark of the 'academic literacies' approach. Students also greatly valued the ISS tutor's 'academic literacies' approach enabled by brokering which involved deconstructing assignment requirements and discussing what subject lecturers want from them: in other words, negotiating power, access and transparency.

It is hoped that this research has contributed to the 'academic literacies' pedagogy in relation to supporting international students and learning development practice. It is also worth adding that where academic literacy support is outsourced to central services, 'academic literacies' expertise (of which there is plenty, see Lillis et al, 2016) may continue to be somewhat siloed and have limited capacity to influence or interrogate practice or further the development of an 'academic literacies pedagogy'. In addition, centralised learning developers will remain undervalued and underpaid, instructed to mostly work with students (Russell et al 2009, p.404). However, when learning developers are situated in practice, and work alongside and collaborate with discipline colleagues, they have the opportunity to influence as the responses from subject lecturers in this paper confirm. However, changes in practice will not occur if the collaboration merely results in adjunct, tailored, study skills sessions. It is only when learning development occupies its own space within a learning community from where it can broker between students and discipline practices, that it can influence those practices.

\section{References}


Barab, S.A. and Duffy, T. (2000) 'From practice fields to communities of practice', in Jonassen, D. and Land, S.M. (eds.) Theoretical foundations of learning environments. Mahwah, NJ: Lawrence Erlbaum Associates, pp. 25-56.

Biggs, J. (2003) Teaching for quality learning at university. Buckingham: Society for Research into Higher Education and Open University Press.

Bourdieu, P. (1986) 'The forms of capital', in Richardson, J. (ed.) Handbook of theory and research for the sociology of education. New York: Greenwood, pp. 241-258.

Burt, R. (2005) Brokerage and closure: an introduction to social capital. Oxford: Oxford University Press.

Cooperrider, D.L., Whitney, D. and Stavros J.M. (2008) Appreciative inquiry handbook: for leaders of change. Williston, VT: Berrett-Koehler.

Cousin, G. (2009). Researching learning in higher education: an introduction to contemporary methods and approaches. New York, NY: Routledge.

Fallon, G. and Berman Brown R. (1999). 'What about the workers? Academic staff opinions about working with non-UK postgraduate students in higher education', Journal of Further and Higher Education, 23(1), pp. 41-52.

Gourlay, L. (2009) 'Threshold practices: becoming a student through academic literacies', London Review of Education, 7(2), pp. 181-192.

Halic, O., Greenberg, K. and Paulus, T. (2009) 'Language and academic identity: a study of the experiences of non-native English speaking international students', International Education, 38(2), pp. 73-93.

Hall, G. and Sung, T. (2009) 'Mind the gap? A case study of the differing perceptions of international students and their lecturers on postgraduate business programmes', International Journal of Management Education, 8(1), pp. 53-62. 
Jackson, N. (2003) Engaging and changing higher education through brokerage.

Basingstoke: Ashgate.

Jezewski M.A., (1990) 'Culture brokering in migrant farmworker health care', Western Journal of Nursing Research, 12(4), pp. 497-513.

Jezewski, M.A. and Sotnik, P. (2001) Culture brokering: providing culturally competent rehabilitation services to foreign-born persons. New York: Center for International Rehabilitation Research Information and Exchange.

Kingston, E. and Forland, H. (2008) 'Bridging the gap in expectations between international students and academic staff', Journal of Studies in International Education, 12(2), pp. 204 -221.

Lave, J. and Wenger, E. (1991) Situated learning: legitimate peripheral participation. Cambridge: Cambridge University Press.

Lea, M. (2004) 'Academic literacies: a pedagogy for course design', Studies in Higher Education, 29(6), pp. 739-756.

Lea, M. and Street, B. (1998) 'Student writing in higher education: an academic literacies approach', Studies in Higher Education, 11(3), pp. 182-199.

Lea, M. and Street, B. (2006) 'The "academic literacies" model: theory and applications', Theory into Practice, 45(4), pp. 368-377.

Lillis, T. and Scott, M. (2007) 'Defining academic literacies research: issues of epistemology, ideology and strategy', Journal of Applied Linguistics, 4(1), pp. 5-32.

Lillis, T., Harrington, K., Lea, M. and Mitchell, S. (eds.) (2016) Working with academic literacies: case studies towards transformative practice. Fort Collins, Colorado: The WAC Clearinghouse/Parlor Press.

Perry, K.H. (2009) 'Genres, contexts, and literacy practices: literacy brokering among Sudanese refugee families', Reading Research Quarterly, 44(3), pp. 256-276. 
Reed, J. (2007). Appreciative inquiry: research for change. London: Sage.

Russell, D. R., Lea, M., Parker, J., Street, B. and Donahue, T. (2009) 'Exploring notions of genre in "academic literacies" and "writing across the curriculum": approaches across countries and contexts', English Publications, 192, pp. 395-423 [online]. Available at: https://lib.dr.iastate.edu/engl pubs/192 (Accessed: 8 June 2019).

Ryan, J. and Carrol, J. (2005) 'Canaries in the coalmine': international students in Western universities', in Carroll, J. and Ryan J. (eds.) Teaching international students: improving learning for all. London: Routledge, pp. 1-10.

Saldana, J. (2009). The coding manual for qualitative researchers. London: Sage.

Samimy, K., Kim, S., Ah Lea, J. and Kasai, M. (2011) 'A participative inquiry in a TESOL program: development of three NNES graduate students' legitimate peripheral participation to fuller participation', Modern Language Journal, 95(4), pp. 558-574.

Shreeve, A. (2007) 'Learning development and study Support - an embedded approach through communities of practice', Art, Design and Communication in Higher Education, 6(1), pp. 11-25.

Stage, F.K. and Manning, K. (1992) (eds.) Enhancing the multicultural campus environment: a cultural brokering approach. San Francisco: Jossey-Bass.

Taha, N. and Cox, A.M. (2010) 'Social network dynamics in international students' learning', in Dirckinck-Holmfeld, L., Hodgson, V., Jones, C., de Laat, M., McConnel, D. and Ryberg, T., (eds.) Proceedings of the 7th international conference on networked learning 2010, Aalborg, Denmark 3-4 May 2010, pp. 396-403 [online]. Available at: http://eprints.whiterose.ac.uk/10858/1/Taha.pdf (Accessed: 8 June 2019)

Wenger, E. (1998) Communities of practice. Cambridge: Cambridge University Press. 
Wenger, E. (2001) 'Communities of practice and social learning systems', Organization 7(2), pp. 225-246.

Wenger-Trayner, E. and Wenger-Trayner, B. (2011) What is a community of practice? Available at: http://wengertrayner.com/resources/what-is-a-community-of-practice/ (Accessed 8 June 2019).

Wingate, U. (2006) 'Doing away with "study skills”', Teaching in Higher Education, 11(4), pp. 457-469.

Wingate, U. (2011) 'Using academic literacies and genre-based models for academic writing instruction: a "literacy" journey', Journal of English for Academic Purposes, 11(1), pp. 26-37.

Wingate U. (2015) Academic literacy and student diversity: the case for inclusive practice. Bristol: Multilingual Matters.

\section{Author details}

Lynne Gornall is a learning development practitioner and senior lecturer at the University of Central Lancashire where she works with both students and colleagues. Her research interests focus on 'academic literacies' and making learning equally accessible for all students. 